\title{
DEVELOPMENT AND VALIDATION OF THREE-DIMENSIONAL HUMAN RANGE OF MOTION MEASUREMENT SYSTEM
}

\author{
Li YAN-XIA ${ }^{1 *}$, Li LIN ${ }^{2}$ and Zhang CHONG-LONG ${ }^{2}$
}

${ }^{1}$ College of Physical Education, Langfang Teachers University, Lang Fang, Hebei, Postal code 065000, China

${ }^{2}$ Department of Physical Education, Renmin University of China, Beijing, postal code 100872, China

*Corresponding author: xiaoxiali529@163.com

(Received May 2018; accepted July 2018)

Key words: the range of motion, inertial sensor technology, sports biomechanics

\begin{abstract}
Three-dimensional human range motion measurement system is developed by inertial sensor technology and wireless bluetooth acquisition technology. This paper describes the internal structure and the data processing method of the measurement system in detail. This measurement system is capable of testing the range of each joint motion, and can be easily carried to the rehabilitation hall, wards and other occasions for test and evaluation. It plays an extremely important role in its application in monitoring rehabilitation process, assessing disability, doing scientific research, and in many other fields. Three experienced teachers tested the range of motion of cervical spine, lumbar spine, right side of the shoulder, elbow, wrist, hip, knee, ankle, and other joints of ten college students. Through comparing the test results and the obtained results of this measurement system by using the method of paired samples T-test, they got the results that the bilateral significance level ( $\mathrm{Sig}$ ) was greater than 0.05 , which can be considered that there were no significant differences between these two sets of results. Then it verifies the validity of the data in this system.
\end{abstract}

Palabras clave: rango de movimiento, tecnología de sensor inercial, biomecánica del deporte

\section{RESUMEN}

Se desarrolló un sistema de medición del rango humano de movimiento tridimensional por medio de un sensor de inercia y con adquisición de datos por tecnología inalámbrica (bluetooth). Este trabajo describe en detalle la estructura interna y el método del procesamiento de datos del sistema de medición. El sistema es capaz de probar el rango de movimiento de cada articulación y puede ser transportado con facilidad a las salas de rehabilitación y a otros pabellones para prueba y evaluación. Tiene un papel muy importante en el monitoreo del proceso de rehabilitación, para evaluar la discapacidad, en la investigación científica y en muchos otros campos. Tres profesores experimentados probaron el rango de movimiento de la espina cervical y lumbar, el lado derecho del hombro, el codo, la muñeca, la cadera, el tobillo y otras articulaciones de diez estudiantes universitarios. Al comparar, por medio de la prueba de T de muestras pareadas, los resultados de pruebas con los obtenidos con el sistema de medición, se obtuvo una relación significativa bilateral mayor que 0.05 , por lo que puede considerarse que no hay diferencias significativas entre los dos grupos de resultados. Por lo tanto, se comprueba la validez de los datos de este sistema. 


\section{INTRODUCTION}

The range of motion (ROM) refers to the range of the movement of a joint from its beginning to its end. The evaluation of the range of motion is the primary assessment process to some physical function disorders, such as arthritis, fractures, burns and hand injuries, etc., which can cause the limitation of joint motion. Traditional tools used to measure the ROM are protractors. However, the application of measuring the ROM by protractors has many disadvantages. First, the test results are not accurate because of the impact of human factors in determining the osseous mark of the joint, aligning the axis of the protractor with the joint axis, and making the fixed arm and the movable arm of the protractor parallel to the proximal and distal bone axis (Mohamad Zainal et al. 2017; Razali et al. 2017). Usually, several doctors may have very different test results towards the same joint of the same subject. Second, the traditional measuring process of using protractor is cumbersome, which costs a very long time and gives a large burden to physicians and patients. Finally, it is easy to generate medical disputes due to the artificial measurement of the test result, especially during the disability appraisal process of CDPF hospital, because the results of the ROM test related to the disability appraisal levels and economic interests, which is easy to produce legal disputes ( $\mathrm{Lu}$ et al. 2018). In order to solve the above problems existing in the traditional measuring process of the ROM by using protractors, and to make the measurement of the motion of each human joint convenient and fast, three-dimensional human range of motion measurement system is developed ( $\mathrm{Ji}$ and Li 2000; Zhao and Li 2008).

\section{TEST PRINCIPLE AND METHOD}

Three-dimensional human range of motion measurement system includes a homemade attitude measurement system based on inertial sensor. The system can output a high precision attitude angle of high precision and other data. Fix the proximal aspect of the subject's test joint and tie the inertial sensor to the distal aspect of the test joint by straps. The distal part of the test joint does the greatest range of motion in each axis direction, and at the same time the inertial sensor does the same movement with the joint and updates and records the largest angle values on the three-axis, which are the values of the range of motion ( $\mathrm{Gu}$ and Zhang 2018). Therefore, it is convenient to record the largest ranges of angle value of the test joint on every axis, which is the range of joint motion. The three-dimensional attitude output is defined as the position between inertial sensors itself coordinate $\mathrm{S}$ and the earth-fixed coordinate $\mathrm{G}$. It uses the earth-fixed coordinate $\mathrm{G}$ as the reference coordinate system and follows Descartes' right-hand rule (Fig. 1).

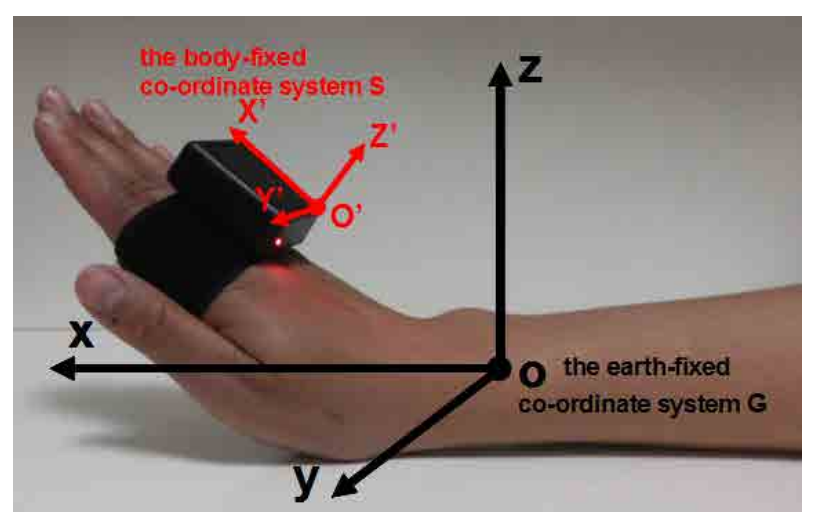

Fig. 1. Definition of coordinate system

\section{SYSTEM COMPOSITION}

\section{System hardware}

Three-dimensional human range of motion measurement system mainly consists of homemade inertial attitude test equipment and test software.

The hardware of the three-dimensional human ROM measurement system mainly includes a homemade attitude measurement system based on inertial sensor. The system can output a high precision attitude angle of high precision and other data. The internal structure of the system includes the inertial sensor section, ARM processor section and Bluetooth wireless transmission section (Fig. 2).

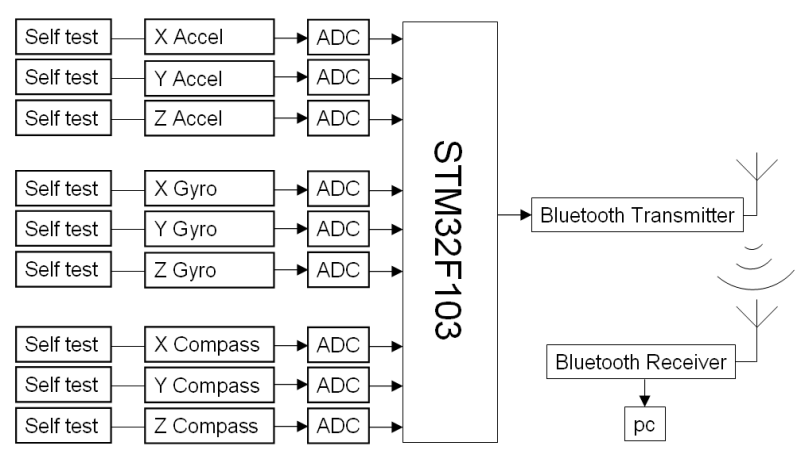

Fig. 2. Internal structure of attitude measurement system 
Inertial sensor section includes three orthogonal collocation micro gyroscopes, three accelerometers and three micro-micro-magnetometers. They are directly fixed on the movement link. The signal is measured to be angular rate, linear acceleration, and magnetic force value, which moves along the axis of movement link coordinate system, and these values are relative to the inertial space. The data are collection frequency $100 \mathrm{~Hz}$, angular velocity measurement range $\pm 1200^{\circ} / \mathrm{s}$, linear acceleration measurement range $\pm 16 \mathrm{~g}$, magnetometer measurement range $\pm 1200 \mu \mathrm{T}$ ( $\mathrm{Li}$ and Zhao 2012; Hu and Ma 2008; Qin and Shi 2009; Ememu and Nwankwoala 2018). Due to a large number of numerical calculations, the control unit adopts 32-bit STM32F103ARM, a single chip microcomputer, which has the ARM Cortex-M3 processor to complete the function of controlling, data collecting and processing, data communicating, and other functions. Through using the normalization method, the linear acceleration data reduces errors caused by the measurement difference of each axis. Adjust the sensor attitude and test the maximum and minimum of each axis. It is measured that the maximum value of the $\mathrm{X}$-axis is $A_{x \max }$, the minimum value of $\mathrm{X}$-axis is $A_{x \min }$; the maximum value of the Y-axis is $A_{y \max }$, the minimum value of Y-axis is $A_{y \text { min }}$; the maximum value of the $Z$-axis is $A_{z \max }$, the minimum value of $\mathrm{Z}$-axis is $A_{z \min }$. The formula of normalization method is as follows:

$$
\left\{\begin{array}{l}
A_{x}=\frac{A_{x}^{\prime}-A_{x \min }}{A_{x \max }-A_{x \min }} \cdot 2-1 \\
A_{y}=\frac{A_{y}^{\prime}-A_{y \min }}{A_{y \max }-A_{y \min }} \cdot 2-1 \\
A_{z}=\frac{A_{z}^{\prime}-A_{z \min }}{A_{z \max }-A_{z \min }} \cdot 2-1
\end{array}\right.
$$

$A_{x}^{\prime} 、 A_{y}^{\prime} 、 A_{z}^{\prime}$ are respectively the actual measurement data at X, Y, Z-axis. $A_{x}{ }^{\prime} 、 A_{y}{ }^{\prime} 、 A_{z}{ }^{\prime}$ are the normalized data. The gyroscope uses three- dimensional turntable to realize full temperature calibration and adopts least-squares linear fit. Then it can correct the integral angle error and can reduce the impact of its drift. By using the method of stereoscopic eight characters calibration, the magnetometer determines the size and direction of the fixed magnetic field interference vectors (Elmnifi et al. 2018). Shake the sensors, which need to be calibrated, in the air, and make its shaking track like an Arabic number eight. Let the normal direction of the sensor point to all eight quadrants of space as much as possible so that we can get enough sample points and can use them to calculate the size and direction of the fixed magnetic field interference vectors. The formula is as follows:

$\left(M_{x}-\gamma_{x}\right)^{2}+\left(M_{y}-\gamma_{y}\right)^{2}+\left(M_{z}-\gamma_{z}\right)^{2}=R^{2}$

$M_{x} 、 M_{y} 、 M_{z}$ are respectively the actual measurement data at X, Y, Z-axis. $\gamma_{x} 、 \gamma_{y} 、 \gamma_{z}$ are respectively the components of the fixed magnetic field interference vectors at $\mathrm{X}, \mathrm{Y}, \mathrm{Z}$-axis. $\mathrm{R}$ is a constant (Kim et al. 2007; Ang et al. 2007; Song and Kin 2009). Use the method of Kalman filter to integrate the collected data and let them be closer to the true value (Chen 1986; Chen and Zhong 2007; Ali et al. 2018). In order to avoid the cardan shaft lock generated by Euler angles, the constructed attitude data uses the quaternion form. The solving equation is as follows:

$\dot{q}=\frac{1}{2} \cdot\left[\begin{array}{cccc}0 & -\omega_{x} & -\omega_{y} & -\omega_{z} \\ \omega_{x} & 0 & \omega_{z} & -\omega_{y} \\ \omega_{y} & -\omega_{z} & 0 & \omega_{x} \\ \omega_{z} & \omega_{y} & -\omega_{x} & 0\end{array}\right] \cdot q$

$q$ is a quaternion vector. $\omega_{x} 、 \omega_{y} 、 \omega_{z}$ are the components of $\omega$. Through solving the above equation, we get the attitude expressed by quaternion. However, as the quaternion form cannot intuitively express the angle change of each axis, we turn the quaternion into the form of Euler angle. The formula is as follows:

$\left\{\begin{array}{l}\varphi=\tan ^{-1}\left(\frac{2 q_{2} q_{3}+2 q_{0} q_{1}}{2 q_{0}^{2}+2 q_{3}^{2}-1}\right) \\ \theta=-\sin ^{-1}\left(2 q_{1} q_{3}-2 q_{0} q_{2}\right) \\ \psi=\tan ^{-1}\left(\frac{2 q_{1} q_{2}+2 q_{0} q_{3}}{2 q_{0}^{2}+2 q_{1}^{2}-1}\right)\end{array}\right.$

$q_{0} 、 q_{1} 、 q_{2}$ and $q_{3}$ are the components of $q \cdot \varphi \cdot \theta, \psi$ are respectively the rotation angle, pitch angle and heading angle of Euler angles (Fig. 3). (John et al. 2009; Damsgaard et al. 2006; Tang et al. 2009; John et al. 2008; Abija and Nwankwoala 2018).

Finally, the navigation parameters are processed into the required data format. Add data header and parity bit to the data to reduce possible misreading of Bluetooth wireless when transmitting. The data is transmitted from Bluetooth transmission to the Bluetooth receiver which is connected to the computer. Then it enters the software which is running on the computer. 


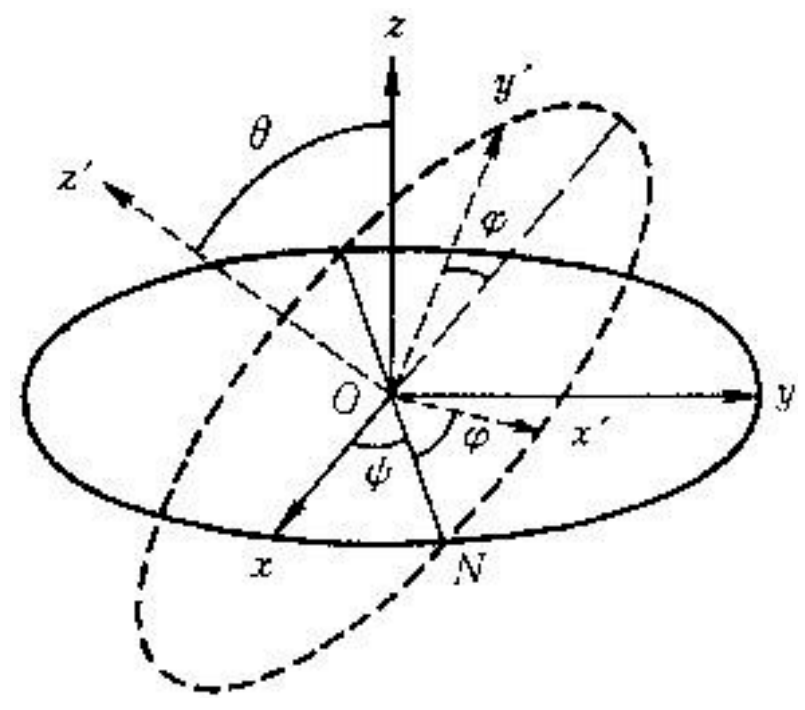

Fig. 3. Definition of Euler angles

\section{System software}

Three-dimensional human ROM measurement system software can be run on windows operating system platform. It is written in $\mathrm{VC}++6.0$ language, and is composed of three modules: subjects' database, test interface and test results analysis interface.

Subjects database manages the information of the subjects, such as name, gender, age, height, weight, etc. The information can be easily added, modified, deleted, searched or else. Test interface includes a control window, a display of a threedimensional skeleton model in the test, a display of a histogram of the test data, the maximum range of motion for each axis direction, and other data displays (Aldaihani and Alenezi 2017). The data names in the software will automatically change with the actual test joints. For example, when testing the cervical range of motion, the pitch angle, rotation angle, and heading angle of Euler angles are respectively corresponding to the flexion and extension, lateral flexion, and the rotary joint angle of the cervical spine. Software testing interface is shown in Fig.4. Test result analysis interface includes longitudinal data analysis for single person and lateral data analysis for multiple people. Data display includes numeric display, two-dimensional and three-dimensional histograms, graphs, pie charts, box diagrams, overlay charts, scatter plots and other statistical data displays. And the analysis results can be printed (Fluit et al. 2012; Lemieux et al. 2012; Jasielec et al. 2012; Hanafiah et al. 2017).

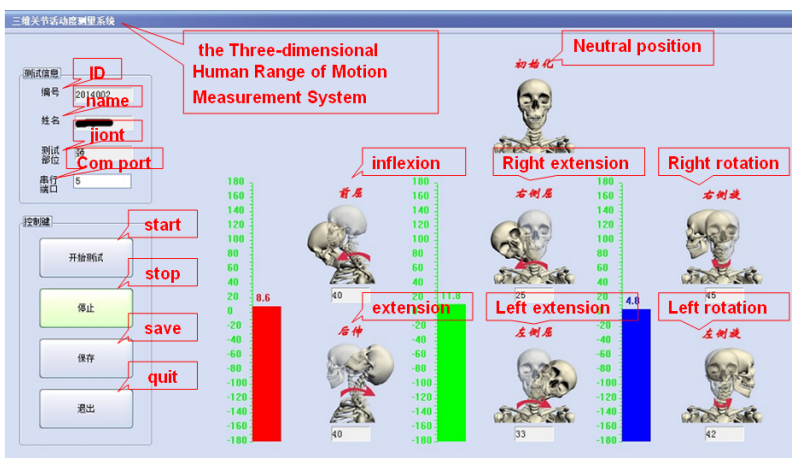

Fig. 4. Three-dimensional human ROM measurement system software test interface

\section{EXPERIMENTAL TEST}

After the three-dimensional human ROM measurement system has been completed, the following experimental test was carried out at the biomechanics class of the undergraduate students in Beijing Normal University. When performing the experiment, the class was divided into many groups in the form of groups of three. In each group, one person operated a computer, one played a role of a subject, and the last person assisted the test. After the test, they took turns to act as subjects, and every one of them was tested once. The assistant student fixed the proximal aspect of the subject's test joint and tied the inertial sensor to the distal aspect of the test joint by straps. The student, who used computer, operated system software, entered subjects database, inputted the subject information, entered the test interface, clicked the Start button, and established a connection between the sensor and the computer so that the subjects' test joints remain in a neutral position, and clicked Initialize button to make $\mathrm{X}, \mathrm{Y}, \mathrm{Z}$-axis direction angle value return to zero. After heard the command to start, the subject initiatively let the test joint do the greatest range of motion in each axis direction. The computer software automatically recorded the maximum and minimum values at each axis direction, which are the values of the range of joint motion. The cervical spine, lumbar spine, right side of the shoulder, elbow, wrist, hip, knee, ankle and other joints of each student were tested for its range of motion. Moreover, the results of each test joint of every subject were recorded three times.

\section{VALIDITY CHECK}

In order to test the performance of three-dimensional human ROM measurement system, in 
TABLE I. PAIRED SAMPLE TEST

\begin{tabular}{|c|c|c|c|c|c|c|c|}
\hline \multirow{2}{*}{ mean value } & \multirow{2}{*}{$\begin{array}{l}\text { standard } \\
\text { deviation }\end{array}$} & \multirow{2}{*}{$\begin{array}{c}\text { standard error of } \\
\text { mean }\end{array}$} & \multicolumn{2}{|c|}{$95 \%$ confidence interval of differential } & \multirow{2}{*}{$\mathrm{t}$} & \multirow{2}{*}{ df } & \multirow{2}{*}{ Sig. (bilateral) } \\
\hline & & & lower limit & upper limit & & & \\
\hline 1.28 & 4.34 & 1.61 & -2.44 & 5.12 & 0.85 & 7 & 0.48 \\
\hline
\end{tabular}

the above experimental test, ten male students who were at the biomechanics class of the undergraduate students in Beijing Normal University were randomly selected (They were $22.3 \pm 1.34$ years old, $175.2 \pm 3.24 \mathrm{~cm}, 69.3 \pm 5.72 \mathrm{~kg}$ ). The cervical spine, lumbar spine, right side of the shoulder, elbow, wrist, hip, knee, ankle and other joints of these ten students were tested for its range of motion by three experienced teachers. The results of each student were recorded three times. And the average of the results was taken.

In SPSS software environment, the two sets of data were conducted normality test analysis. Finally, they were tested through paired samples T-test method (John et al. 2008; Han et al. 2013). Table I shows the test results. In the table, ROMSys is the test data of the three-dimensional human range of motion measurement system. Manual is manual test data (Masuko et al. 2005; Nimbarte et al. 2003; Boren et al. 2009). From the statistical data in Table I, it is known that after the paired samples T-test, the bilateral significance level (Sig) was greater than 0.05 , which can be considered that there were no significant differences between these two sets of results.

\section{CONCLUSION}

This study develops a three-dimensional human range of motion measurement system. And this measurement system is capable of testing the range of each joint motion, and can be easily carried to the rehabilitation hall, wards and other occasions for test and evaluation. It plays an extremely important role in its application in monitoring rehabilitation process, assessing disability, doing scientific research, and in many other fields. Through the comparative analysis of the data obtained respectively by threedimensional human range of motion measurement system and artificial method, the validity of the data in this system is verified.

\section{ACKNOWLEDGMENTS}

This work was funded by the Ministry of Education of Humanities and Social Science project (11YJA88003).

\section{REFERENCES}

Abija, F.A., and Nwankwoala, H.O. (2018). Characterization of Aquifers in Parts of Abia State South-eastern Nigeria. Earth sci. Pak. 2 (1), 18-22.

Aldaihani, N., and Alenezi, R. (2017). Estimation of CO2 Emissions of The Vehicles Transport Sector In The State Of Kuwait. Acta chem. Malay. 1 (1), 08-12.

Ali, W., Nasir, M.S., Nasir, A., Rashid, H., Ayub, I., Gillani, S.H., and Latif, M.J. (2018). Assessment of Carbon Footprints in Terms of Co2 Of Diesel Generator, Pakistan. Earth sci. Pak. 2(1), 15-17.

Ang, W.T., Khosal, P.K. and Riviere, C.N. (2007). Feedforward controller with inverse rate-dependent model for piezoelectric actuators in trajectory-tracking applications. IEEE Sens. J., 12 (2), 134-142.

Boren, J.L., Ojeda and Kwamuang, S. (2009). Heuristic reduction of gyro drift for personnel tracking systems. J. Navigation., 62 (1), 41-58.

Chen, Y.B. and Zhong, B. (2007). Inertial Navigation Principles. Defense Industry Press, Beijing.

Chen, Z. (1986). Strapdown Inertial Navigation System Principle. China Aerospace Press, Beijing.

Damsgaard, M.J., Rasmussen, R.T., Christensen, S.T., Surma, E. and Zee, M. (2006). Analysis of musculoskeletal systems in the AnyBody Modeling System. Simul. Model. Pract. Th., 14, 1100-1111.

Elmnifi, M., Alshelmany, M., Alhammaly, M. and Imrayed, O. (2018). Energy Recovery from Municipal Solid Waste Incinerati on Benghazi - Case Study. Eng. herit. j. 2(1), 19-23.

Ememu, A.J. and Nwankwoala, H.O. (2018). Application of Water Quality Index (Wqi) For Agricultural and Irrigatio nal Use Around Okpoko, Southeastern Nigeria. Eng. herit. j., 2(1), 14-18. 
Fluit, R., van der Krogt, M.M., van der Kooij, H., Verdonschot, N.H. and Koopman. (2012). A simple controller for the prediction of three-dimensional gait. J. Biomech., 45 (15), 2610-2617.

Gu, J. and Zhang, D. (2018). Analysis on Influencing Factors of Industrial Pollution taking Zhejiang Province as an Example. Acta sci. Malays., 2(1), 14-16.

Han, K.S., Rohlmann, A., Zander, T. and Taylor, W.R. (2013). Lumbar spinal loads vary with body height and weight. Med. Eng. Phys., 35 (7), 969-977.

Hanafiah, M.M., Ali, M.Y.M., Aziz, N.I.H.A. and John, A. (2008). Biogas Production from Agro-waste And Effluents. Acta chem. Malay., 1 (1), 13-15.

Hu, S.F. and Ma, J.C. (2008). Aeronautical Computing Technique., 115, 38.

Jasielec, J.J., Filipek, R., Szyszkiewicz, K., Fausek, J., Danielewski, M. and Lewenstam, A. (2012). Computer simulations of electrodiffusion problems based on Nernst-Planck and Poisson equations. Comput. Mater. Sci. 63, 75-90.

Ji, Z.Q. and Li, J.S. (2000). Sports Biomechanics. Higher Education Press, Beijing.

John, Z.W., An, K.N., Cutlip, R.G., Krajnak, K., Welcome, D. and Dong, R. (2008). Analysis of musculoskeletal loading in an index finger during tapping. J. Biomech., 41 (3), 668-676.

John, Z.W., Dong, R.G., McDowell, T.W. and Welcome, D.E. (2009). Modeling the finger joint moments in a hand at the maximal isometric grip: The effects of friction. Med. Eng. Phys., 31, 1214-1218.

Kim, S.G., Crassidis, J.L., Cheng, Y., Fosbury, A.M. and Junkins, J.L. (2007). Kalman Filtering for Relative Spacecraft Attitude and Position Estimation. J. Guid. Control Dyn. 30 (1), 133-143.

Lemieux, P.O., Nuño, N., Hagemeister, N. and Tétreault, P. (2012). Mechanical analysis of cuff tear arthropathy during multiplanar elevation with the AnyBody shoulder model. Clin. Biomech., 27 (8), 801-806.
Li, Y.J. and Zhao, Z.X. (2012). Data Acquisition and Processing., 502, 4.

Li, Y.L. (2008). Beijing: People's Health Press.124, 4.

Lu, Z., Daxing, X. and Hailun, W. (2018). Two-Stage Cubature Kalman Filter and its Application in Water Pollution Model. Acta sci. Malays., 2(1), 09-13.

Masuko, T., Minami, A., Iwasaki, N., Majima, T., Nishimura, S. and Lee, Y.C. (2005). Carbohydrate analysis by a phenol-sulfuric acid method in microplate format. Anal Biochem., 339 (1), 69-72.

Mohamad Zainal, N.S.L., Omar, S.M. and Ashaari, M.M. (2017). Isolation and Characterization of Biosurfactant-Producing Bacteria Isolated from Petroleum Contaminated Sites with The Potential to Be Used in Bioremediation. Sci. Herit. j., 1(2), 11-15.

Nimbarte, D.A.S., Yun, Jaridi, M. and Hsiao, H. (2009). Biomechanical loading of the shoulder complex and lumbosacral joints during dynamic cart pushing task. Appl. Ergonomics., 44 (5), 841-849.

Qin, H. and Shi, B.H. (2009). Electronics Process Technology., 32, 30.

Razali, A., Zuraidah, M.A., Akbar John, B. and Kamaruzzaman, Y. (2017). Cytotoxicity on Mcf7 Cell Lines Exposed to An Extract of The Jacalin From Jackfruit Seed. Sci. herit. j., 1 (2), 16-18.

Song, L.J. and Qin, Y.Y. (2009). Measurement and Control Technology., 11, 28.

Tang, H., Buehler, M.J. and Moran, B. (2009). A Constitutive Model of Soft Tissue: From Nanoscale Collagen to Tissue Continuum. Ann. Biomed. Eng., 37 (6), 1117-1130.

Zhao, H.B. and Li, J.S. (2008). Sports Biomechanics. Higher Education Press, Beijing. 